\title{
Antimicrobial resistance and virulence factor gene profiles of Enterococcus spp. isolated from giant panda oral cavities
}

\author{
Rui Zhong, Ziyao Zhou, Haifeng Liu, \\ Zhijun Zhong, Guangneng Peng ${ }^{\bowtie}$ \\ College of Veterinary Medicine, Sichuan Agricultural University, \\ Key Laboratory of Animal Disease and Human Health of Sichuan, Chengdu, 611130, China \\ pgn.sicau@163.com
}

Received: October 20, $2020 \quad$ Accepted: May 14, 2021

\begin{abstract}
Introduction: The objective of this study was to determine the prevalence and characteristics of antimicrobial-resistant Enterococcus faecalis and E. faecium isolated from the oral cavities of captive giant pandas in China. Material and Methods: The virulence-associated determinant and antimicrobial resistance genes were detected and antimicrobial susceptibility tests were performed on 54 strains of each bacterium. Results: All isolates showed 100\% multidrug resistance. E. faecalis isolates showed a higher percentage of strains resistant to gentamicin (48.1\%), vancomycin (55.6\%), linezolid (100\%), and streptomycin (33.3\%) than $E$. faecium isolates. The resistance genes of Enterococcus spp. were present to highly varying extents according to antibiotic type, their presence breaking down for E. faecalis and E. faecium respectively as aac (6')/aph( $\left.2^{\prime \prime}\right) 5.56 \%$ and $5.56 \%$; aph $\left(3^{\prime}\right)$ - III $0 \%$ and $14.81 \%$; ant (6)-I $0 \%$ and $3.7 \%$; ant $\left(4^{\prime}\right)-I a 0 \%$ and $64.81 \%$; tetL $20.37 \%$ and $100 \%$; vanA $92.59 \%$ and $46.3 \%$; vanB $0 \%$ and $0 \%$; cfr $0 \%$ and $90.74 \%$; optrA $96.3 \%$ and $3.7 \%$; blaZ $0 \%$ and $1.85 \%$; blaTEM $0 \%$ and $0 \%$; tetA $20.37 \%$ and $0 \%$; tetC $24.07 \%$ and $100 \%$; tet $M 0 \%$ and $0 \%$; ermA $12.96 \%$ and $100 \%$; ermB $5.56 \%$ and $3.7 \%$; and ermC $0 \%$ and $1.85 \%$.Virulence-associated determinants were detected in this research, which typically include efaA, gelE, asal, ace, cylA, esp and hyl; however, the latter three were not detected. High proportions of the isolates carried the efaA, gelE, asal, and ace genes. Respectively for E. faecalis and E. faecium their detection was efaA $98.1 \%$ and $85.2 \%$; gelE $98.1 \%$ and $87 \%$; asal $92.6 \%$ and $87 \%$; and ace $87 \%$ and $85.2 \%$. Conclusion: This is the first study on the potential disease risk and antimicrobial-resistant characteristics of E. faecalis and E. faecium isolates in giant panda oral cavities. The results of this study show that the antimicrobial resistance rate of Enterococcus spp. isolated from the oral cavity of captive pandas is very high, and thus needs to be monitored.
\end{abstract}

Keywords: Enterococcus spp., giant panda, antimicrobial resistance, resistance genes, virulence factors.

\section{Introduction}

Enterococcus spp. are natural bacteria in the gut of both humans and animals. As an opportunistic pathogen, it can cause infection when animal immunity is low. The Enterococcus genus presently contains over 50 species, among which E. faecalis and E. faecium dominate, accounting for more than $80 \%$ of isolates. In addition, Enterococcus spp. have become the second most common iatrogenic infection causing bacteria after Staphylococcus aureus. E. faecalis is of great importance as a leading opportunistic pathogen causing nosocomial infections, the frequent types of which include endocarditis, meningitis, and urinary tract, wound, and neonatal infections (2).

While Enterococcus spp. are not regarded as normal inhabitants of the oral cavity, they have been isolated from samples from patients with various oral conditions including carious lesions, periodontitis, root canal infection (38) and peri-implantitis (15). Some researchers believe that the pathogenic mechanism of Enterococcus spp. in the oral cavity may be related to the ability to form recalcitrant biofilms in the root canal (28) and carry virulence factors. The most studied virulence-associated determinants are aggregation substances, surface adhesins, sex pheromones, lipoteichoic acid, 
production of extracellular superoxide, gelatinase, hyaluronidase, and the cytolysin toxin (21). In addition, E. faecalis from the oral cavity not only causes pulp disease, but also has the ability to colonise other tissue and infect it systemically, e.g. in the form of endocarditis (25).

Due to their ubiquity in human and animal faeces and persistence in the environment, Enterococcus spp. are considered indicators of faecal contamination in water. Moreover, Enterococcus spp. serve as important key indicator bacteria for human and veterinary resistance surveillance systems. Antimicrobial-resistant Enterococcus spp. have the potential to cause zoonotic diseases, being possessed of intrinsic resistance to various antimicrobial agents including aminoglycosides and cephalosporins, and able to acquire resistance genes from other bacteria by conjugation via plasmids or transposons and bacteriophages (11). This phenomenon has led to an increase in the prevalence rate of multidrug resistant (MDR) Enterococcus spp.

Information on the antimicrobial susceptibility characteristics of Enterococcus spp. isolates from the giant panda oral cavity is scarce. Only a small amount of metagenome analysis has been done on the bacterial composition of this microbiome. The first aim of the present study was to take this analysis further, focusing on selected resistance genes as well as additional relevant phenotypic resistance to assess whether the isolated strains could represent a reservoir for antimicrobial resistance traits. The second aim was to evaluate the major virulence traits of Enterococcus spp. isolates.

\section{Material and Methods}

Bacterial strains. A total of 108 strains comprising 54 of E. faecalis and 54 of E. faecium were used for the study and were isolated from sublingual saliva samples of 15 giant pandas. They were collected from captive giant pandas living in the Chengdu Research Base of Giant Panda Breeding in the Sichuan Province, China. All isolates were presumptively identified by phenotypic methods, including Gram staining and Enterococcus spp. chromogenic medium (Hopebiol Biotech, Qingdao, China) growth. We used $16 \mathrm{~S}$ rDNA sequences for final identification and the confirmed isolates were stored in Luria Bertani broth containing $50 \%$ glycerol at $-20^{\circ} \mathrm{C}$ for further analyses.

Antimicrobial susceptibility test. Susceptibility to 10 antimicrobial agents (penicillin (10 U), ampicillin $(10 \mu \mathrm{g})$, ciprofloxacin $(5 \mu \mathrm{g})$, levofloxacin $(5 \mu \mathrm{g})$, erythromycin $(15 \mu \mathrm{g})$, gentamicin $(120 \mu \mathrm{g})$, streptomycin $(300 \mu \mathrm{g})$, tetracycline $(30 \mu \mathrm{g})$, linezolid $(30 \mu \mathrm{g})$, and vancomycin $(30 \mu \mathrm{g}))$ was assessed using the disk diffusion method according to the criteria of the Clinical and Laboratory Standards Institute (6). Drug-sensitive paper was purchased from Hangzhou Microbial Reagent Co.
(Hangzhou, China) and Thermo Fisher Scientific (Waltham, MA, USA). Enterococcus faecalis ATCC 29212 and Staphylococcus aureus ATCC 25923 strains were used for quality control. Isolates resistant to at least one member of three different antimicrobial groups were considered MDR (9).

DNA extraction and screening for antibiotic resistance genes. Total genomic DNA was extracted from isolates using the TIANamp Bacteria DNA kit (Tiangen Biotech, Beijing, China) according to the manufacturer's instructions. DNA samples were stored at $-20^{\circ} \mathrm{C}$.

Seventeen antimicrobial resistance genes were detected using PCR. The primers used in this study are shown in Table 1. All the design sequences utilised in this research were found through GenBank, and then Oligo 7 was used to design the primers. To amplify the $\operatorname{aac}\left(6^{\prime}\right) / \operatorname{aph}\left(2^{\prime \prime}\right)$, aph(3')- III, ant(6)-I, ant(4')-Ia, tetL, van $A$, vanB, blaTEM, cfr, optrA and blaZ genes a single PCR was used. The PCR program and amplification system in part exploit prior knowledge in the literature referenced in Table 1. For detecting the presence of the tet $A, \operatorname{tet} C$, tetM, erm $A$, ermB, and erm $C$ genes, a multiplex PCR was used according to protocols described previously (3).

The PCR products were separated by gel electrophoresis in a 1.0\% agarose gel stained with GoldView (Sangon Biotech, Shanghai, China), visualised under ultraviolet light, and photographed using a gel documentation system (Bio-Rad, Hercules, CA, USA).

Detection of virulence-associated determinants. Bacterial DNA extract was thawed immediately before performing PCR. Genes encoding the asal, gelE, $c y l A$, esp, hyl, ace, and efaA enterococcal virulence factors were detected using PCR under conditions described previously $(20,26,35)$. All primers are shown in Table 2.

\section{Results}

Antimicrobial susceptibility. The results of the resistance of Enterococcus strains to selected antimicrobials are given in Fig.1. The 108 isolates from the saliva of giant pandas from Chengdu showed different degrees of resistance to 10 antimicrobials.

The drug resistance rates of the 54 Enterococcus faecalis strains were $61.1 \%$ to penicillin, $48.1 \%$ to gentamicin, $90.7 \%$ to erythromycin, $55.6 \%$ to vancomycin, $100 \%$ to linezolid, $98.1 \%$ to ciprofloxacin, $33.3 \%$ to streptomycin, $55.6 \%$ to ampicillin, $83.3 \%$ to tetracycline, and $94.4 \%$ to levofloxacin. For the 54 E. faecium isolates, the resistance rates of $90.7 \%$ to penicillin, $100.0 \%$ to erythromycin, $88.9 \%$ to ampicillin, $98.1 \%$ to tetracycline, and $98.1 \%$ to levofloxacin were higher than those of the E. faecalis isolates. 
Table 1. Primers used for PCR detection of antimicrobial resistance genes

\begin{tabular}{|c|c|c|c|c|}
\hline Resistance to & Resistance gene & Primer sequence $\left(5^{\prime} \rightarrow 3^{\prime}\right)$ & Amplicon (bp) & References \\
\hline \multirow{4}{*}{ Aminoglycoside } & $\operatorname{aac}\left(6^{\prime}\right) / \operatorname{aph}\left(2^{\prime \prime}\right)$ & $\begin{array}{l}\text { CCAAGAGCAATAAGGGCATA } \\
\text { CACTATCATAACCACTACCG }\end{array}$ & 220 & this study \\
\hline & $\operatorname{aph}\left(3^{\prime}\right)-I I I$ & $\begin{array}{l}\text { GCCGATGTGGATTGCGAAAA } \\
\text { GCTTGATCCCCAGTAAGTCA }\end{array}$ & 292 & this study \\
\hline & $\operatorname{ant}(6)-I$ & $\begin{array}{l}\text { ACTGGCTTAATCAATTTGGG } \\
\text { GCCTTTCCGCCACCTCACCG }\end{array}$ & 597 & (21) \\
\hline & $\operatorname{ant}\left(4^{\prime}\right)-I a$ & $\begin{array}{l}\text { CTTGGACGCTGAGATATATGAGCACC } \\
\text { GGAAAGTTGACCAGACATTACGAACT }\end{array}$ & 294 & (10) \\
\hline \multirow{4}{*}{ Tetracycline } & tetM & $\begin{array}{l}\text { GAGGTCCGTCTGAACTTTGCG } \\
\text { AGAAAGGATTTGGCGGCACT } \\
\end{array}$ & 900 & (21) \\
\hline & tetA & $\begin{array}{l}\text { GGCACCGAATGCGTATGAT } \\
\text { AAGCGAGCGGGTTGAGAG } \\
\end{array}$ & 480 & (21) \\
\hline & tetC & $\begin{array}{l}\text { CTGGGCTGCTTCCTAATGC } \\
\text { AGCTGTCCCTGATGGTCGT }\end{array}$ & 580 & (21) \\
\hline & tetL & $\begin{array}{l}\text { TGGTCCTATCTTCTACTCATTC } \\
\text { TTCCGATTTCGGCAGTAC } \\
\end{array}$ & 385 & (14) \\
\hline \multirow{2}{*}{ Vancomycin } & vanA & $\begin{array}{l}\text { GGGAAAACGACAATTGC } \\
\text { GTACAATGCGGCCGTTA }\end{array}$ & 732 & (14) \\
\hline & $\operatorname{van} B$ & $\begin{array}{l}\text { CAAAGCTCCGCAGCTTGCATG } \\
\text { TGCATCCAAGCACCCGATATAC }\end{array}$ & 484 & (14) \\
\hline \multirow{2}{*}{$\beta$-lactams } & blaZ & $\begin{array}{l}\text { ACTTCAACACCTGCTGCTTTC } \\
\text { TAGGTTCAGATTGGCCCTTAG }\end{array}$ & 240 & (34) \\
\hline & blaTEM & $\begin{array}{l}\text { CCAATGCTTAATCAGTGAGG } \\
\text { ATGAGTATTCAACATTTCCG }\end{array}$ & 858 & (23) \\
\hline \multirow{3}{*}{ Erythromycin } & ermA & $\begin{array}{l}\text { TCTAAAAAGCATGTAAAAGAAA } \\
\text { CGATACTTTTTGTAGTCCTTC } \\
\end{array}$ & 553 & this study \\
\hline & ermB & $\begin{array}{l}\text { CCGTTTACGAAATTGGAACAGGTAAAGGGC } \\
\text { GAATCGAGACTTGAGTGTGC }\end{array}$ & 359 & this study \\
\hline & erm C & $\begin{array}{l}\text { GCTAATATTGTTTAAATCGTCAATTCC } \\
\text { GGATCAGGAAAAGGACATTTTAC } \\
\end{array}$ & 460 & this study \\
\hline \multirow{2}{*}{ Linezolid } & $c f r$ & $\begin{array}{l}\text { TGAAGTATAAAGCAGGTTGGGAGTCA } \\
\text { ACCATATAATTGACCACAAGCAGC }\end{array}$ & 746 & (32) \\
\hline & optrA & $\begin{array}{l}\text { AGGTGGTCAGCGAACTAA } \\
\text { ATCAACTGTTCCCATTCA }\end{array}$ & 1395 & (5) \\
\hline
\end{tabular}

Table 2. Primers for different virulence genes

\begin{tabular}{|c|c|c|c|c|}
\hline Virulence factor & Genes & Primer sequence $\left(5^{\prime} \rightarrow 3^{\prime}\right)$ & $\begin{array}{l}\text { PCR product } \\
\text { size (bp) }\end{array}$ & References \\
\hline Aggregation substance & asal & $\begin{array}{l}\text { GCACGCTATTACGAACTATGA } \\
\text { TAAGAAAGAACATCACCACGA }\end{array}$ & 375 & (4) \\
\hline Gelatinase & gelE & $\begin{array}{l}\text { TATGACAATGCTTTTTGGGAT } \\
\text { AGATGCACCCGAAATAATATA }\end{array}$ & 213 & (4) \\
\hline Cytolysin & cylA & $\begin{array}{l}\text { ACTCGGGGATTGATAGGC } \\
\text { GCTGCTAAAGCTGCGCTT }\end{array}$ & 688 & (4) \\
\hline Enterococcal surface protein & esp & $\begin{array}{l}\text { AGATTTCATCTTTGATTCTTGG } \\
\text { AATTGATTCTTTAGCATCTGG }\end{array}$ & 510 & $(4$ \\
\hline Hyaluronidase & hyl & $\begin{array}{l}\text { ACAGAAGAGCTGCAGGAAATG } \\
\text { GACTGACGTCCAAGTTTCCAA }\end{array}$ & 276 & (4) \\
\hline Accessory colonization factor & ace & $\begin{array}{l}\text { GAATTGAGCAAAAGTTCAATCG } \\
\text { GTCTGTCTTTTCACTTGTTTC }\end{array}$ & 1108 & $(21)$ \\
\hline Endocarditis antigen & efaA & $\begin{array}{l}\text { GCCAATTGGGACAGACCCTC } \\
\text { CGCCTTCTGTTCCTTCTTTGGC }\end{array}$ & 688 & $(21)$ \\
\hline
\end{tabular}

It is worth noting that all 108 Enterococcus spp. isolates were resistant to three or more classes of antimicrobials. Among the E. faecalis strains, 34 $(62.96 \%)$ isolates were resistant to six different antimicrobial agents, whereas among E. faecium strains only $25(46.3 \%)$ isolates were found to be resistant to the same number of antimicrobials.

Antibiotic resistance genes. The results of investigation of the presence of resistance genes are summarised in Fig. 2. The detection rates of the tet $L$ and tet $K$ genes in E. faecalis isolates were $20.37 \%$ and $24.07 \%$, respectively. However, tetL and tetC were detected in all E. faecium isolates. The tet $M$ gene was not present in any strain of either bacterium.

The ermA gene was detected in all 54 E. faecium isolates and in $12.96 \%$ of those of E. faecalis. In contrast, the detection rates of the ermB and erm $C$ genes in the E. faecium isolates were very low at $3.7 \%$ and 
$1.85 \%$, respectively. In $E$. faecalis isolates, the detection rate of the ermB gene was $5.56 \%$, while erm $C$ was not detected. The $\beta$-lactam resistance gene was in very low presence, with a detection rate of only $1.85 \%$ in E. faecium isolates.

Among E. faecalis isolates, the vanA gene was found in 50 strains $(92.59 \%)$, whereas the vanB gene was not detected. In $E$. faecium isolates, the detection rate of the vanA gene decreased to $46.3 \%$, while the
vanB gene was likewise not detected. For aminoglycoside drugs, we selected four common resistance genes; namely, ant6-I, ant3'-III, aac6'-aph2", and ant $\left(4^{\prime}\right)-I a$. Among the E. faecalis isolates, only the aac6'-aph2" gene was found, and it was identified in 3 strains $(5.56 \%)$. The detection rates of the aminoglycosides resistance genes in E. faecium were $3.7 \%$ for ant6-I, $14.81 \%$ for ant $3^{\prime}-I, 5.56 \%$ for aac $6^{\prime}-a p h 2^{\prime \prime}$, and $64.81 \%$ for $\operatorname{ant}\left(4^{\prime}\right)-I a$.

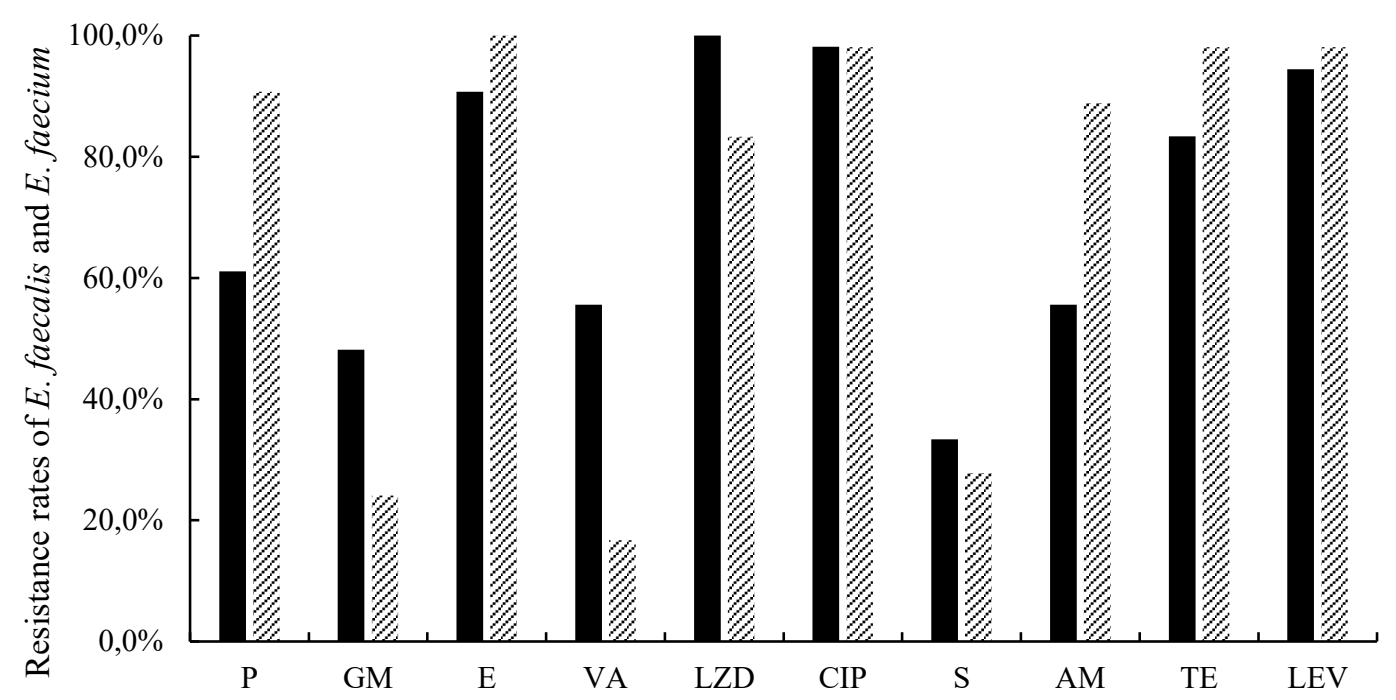

Antimicrobial agents

- E. faecalis $\leadsto$. faecium

Fig. 1. Resistance rates of 54 E. faecalis and 54 E. faecium strains to 10 antibiotics

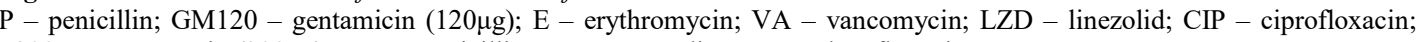

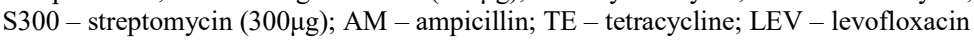

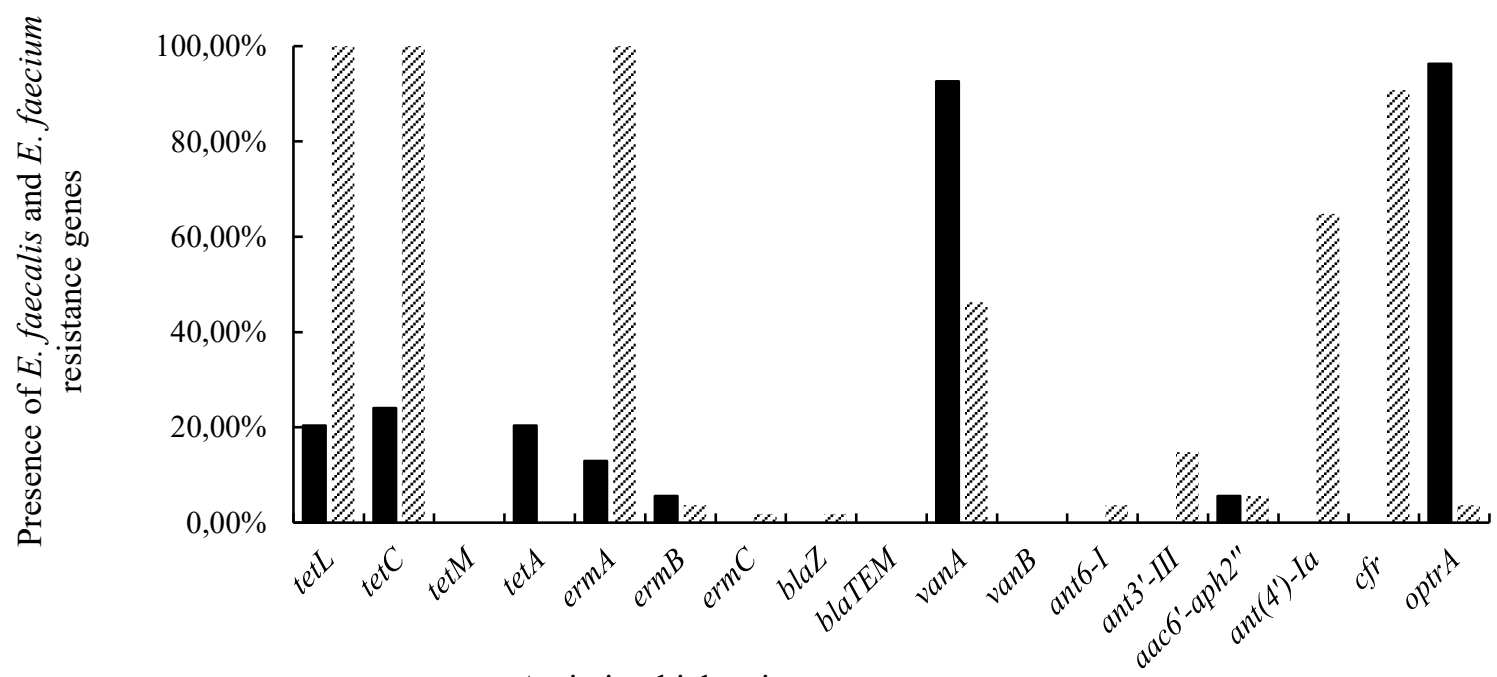

Antimicrobial resistance genes

- E. faecalis $\not /$ E. faecium

Fig. 3. Presence of E. faecalis and E. faecium resistance genes

tet $L$, tet $C$, tet $M$, and tet $A$ - tetracycline resistance genes; erm $A$, erm $B$, and erm $C$ - erythromycin resistance genes; blaZ and blaTEM - $\beta$-lactam resistance genes; vanA and $v a n B$ - vancomycin resistance genes; ant6- I, ant3'- III, aac6'-aph2', and ant(4')-Ia - aminoglycoside resistance genes; $c f r$ and optrA - linezolid resistance genes 


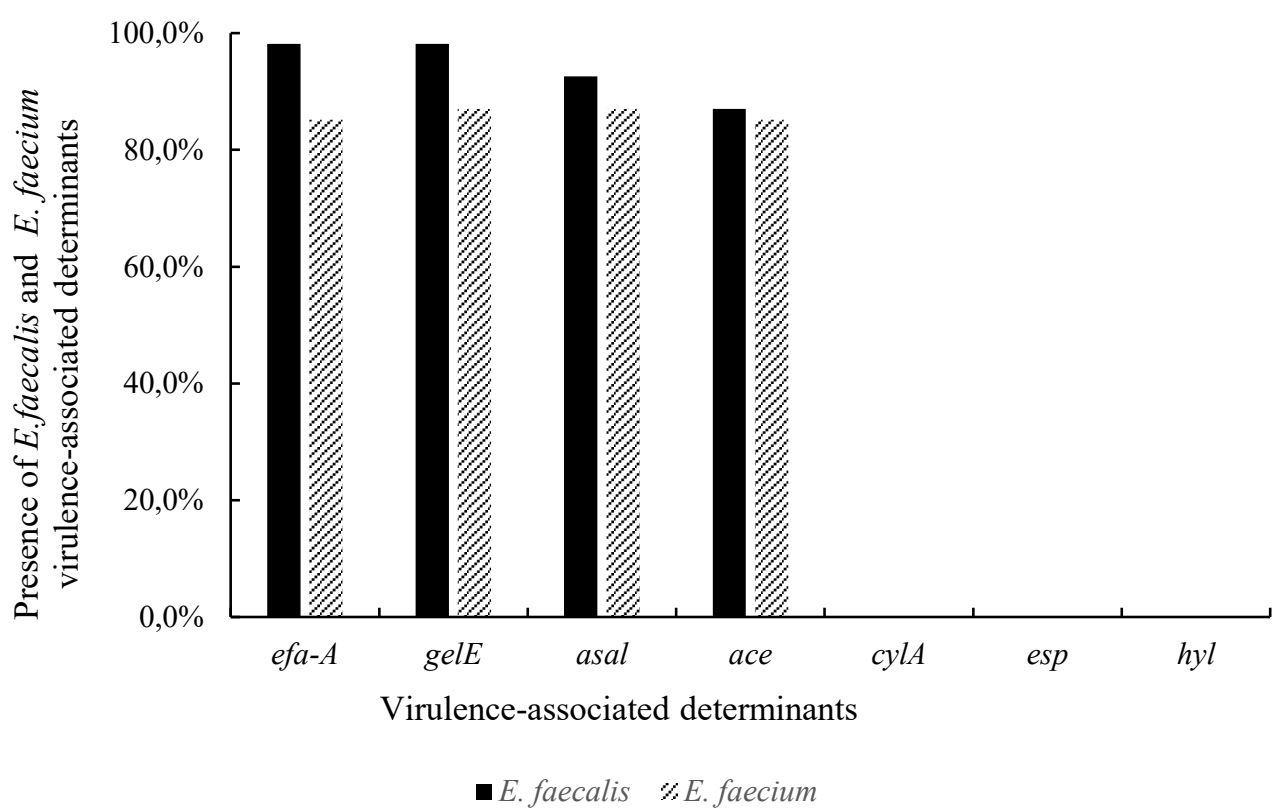

Fig. 3. Presence of $E$. faecalis and $E$. faecium virulence-associated determinants ace - collagen-binding protein; asal - aggregation substance; cylA - cytolysin; efa- $A$ - endocarditis antigen; esp - enterococcal surface protein; gelE - gelatinase; $h y l$ - hyaluronidase

Finally, it is noteworthy that the drug resistance rates of isolates to linezolid were very high in antimicrobial susceptibility test. Both the genes conferring resistance, $c f r$ and optrA, were detected in PCR. However, the detection rate of $c f r$ gene in E. faecium isolates was as high as $90.74 \%$, but no $c f r$ gene was detected in those of E. faecalis. The opposite was true for the optrA gene, which was detected at a rate of only $3.7 \%$ in E. faecium isolates, but at a very high rate of $96.30 \%$ in those of E. faecalis.

Virulence-associated determinants. The results of investigation of the presence of virulence-associated determinants are summarised in Fig. 3.

We tested for the presence of seven virulence factors. The $c y l A$, esp and $h y l$ genes were not detected. All 54 E. faecalis strains yielded the efaA, gelE, asal, and ace genes in abundance, with respective $98.1 \%$, $98.1 \%, 92.6 \%$ and $87.0 \%$ detection rates. The same phenomenon was also observed in the $54 \mathrm{E}$. faecium strains, but the detection rates for these four genes were lower. The most common type of virulence factor carrier was efaA-gelE-asal-ace among both E. faecalis and E. faecium (Tables 3 and 4).

Table 3. Virulence-associated gene profile of $E$. faecalis isolates from giant panda saliva samples

\begin{tabular}{lcc}
\hline Virulence-associated gene & Number of isolates & Proportion \\
\hline efaA-gelE & 2 & $3.70 \%$ \\
gelE-asal & 1 & $1.85 \%$ \\
efaA-ace & 1 & $1.85 \%$ \\
efaA-gelE-ace & 1 & $1.85 \%$ \\
efaA-gelE-asal & 4 & $7.41 \%$ \\
efaA-gelE-asal-ace & 45 & $83.33 \%$ \\
\hline
\end{tabular}

Table 4. Virulence-associated gene profile of E. faecium isolates from giant panda saliva samples

\begin{tabular}{lcc}
\hline Virulence-associated gene & Number of isolates & Proportion \\
\hline efaA-ace & 1 & $1.85 \%$ \\
gelE-asal & 2 & $3.70 \%$ \\
efaA-gelE-asal-ace & 45 & $83.33 \%$ \\
None & 6 & $11.11 \%$ \\
\hline
\end{tabular}

\section{Discussion}

In view of the universal finding of MDR in all the isolates tested and the 34 out of $54(62.96 \%)$ E. faecalis and 25 out of $54(46.30 \%)$ E. faecium strains found to be resistant to six to seven antibiotics, high rates of drug resistance exist in Enterococcus spp. colonising captive giant panda oral cavities, and indicate a severe problem.

Since the 1990s, Enterococcus spp. have emerged as leading nosocomial pathogens and been shown to have the ability to acquire and spread resistance genes readily (38). However, the role of Enterococcus spp. such as E. faecalis that inhabit the oral cavity as a potential reservoir for resistance has not been clarified yet. The emergence of Enterococcus isolates that have multidrug resistance phenotypes, which confer resistance to three or more unrelated families of antibiotics, is considered a serious problem. Increasing resistance to antimicrobials of which tetracycline, rifampicin, ciprofloxacin, and erythromycin are some examples has been reported in E. faecalis (1). The results of this study showed that $98 \%$ of the E. faecalis strains and $98 \%$ of the E. faecium strains were resistant to ciprofloxacin, which is much higher than the $25 \%$ resistance rate reported in India (31) and $38.1 \%$ in Portugal (18). Previous studies have suggested that the 
rampant use of fluoroquinolones has contributed to the emergence of high-level or complete resistance and a high prevalence of MDR (13). Such observations have also been reported in previous studies of human cases of enterococcal urinary tract infections (16). The resistance rate to levofloxacin at $94.4 \%$ was like the rate to ciprofloxacin. Erythromycin, tetracycline and linezolid were found to be resisted by the bacteria in this study as much as quinolones. In our study, $90.7 \%$ of E. faecalis isolates and $100 \%$ of E. faecium isolates were resistant to erythromycin. This result is similar to that of SattariMaraji et al. (30), for whom the resistance rate to erythromycin was close to $100 \%$. The erm $A$ gene had the highest detection rates of the erythromycin resistance genes, being present in $12.96 \%$ and $100 \%$ respectively of E. faecalis and E. faecium isolates. Only low inclusions of $\mathrm{erm} B$ and $\mathrm{erm} C$ were detected, which was inconsistent with the high detection rate of ermB reported by Guerrero-Ramos et al. (10) and Bin et al. (14) in meat products.

The resistance rates of E. faecalis and E. faecium isolates to tetracycline were as high as $83.3 \%$ and $98.1 \%$. The common tetracycline resistance genes tet $L$, tet $C$, tet $A$ and tet $M$ were selected for detection. The rate at which tet $L$ and tet $C$ were detected was high, but the tet $M$ carriage rate was $0 \%$. This is inconsistent with the high detection rates of these genes in isolated strains observed in hospitals by Tian et al. (33).

The optrA gene, which confers transferable resistance to oxazolidinones (linezolid and tedizolid) and phenicols (chloramphenicol and florfenicol), has been detected in E. faecalis and E. faecium isolates of both human and animal origin. This gene encodes an $\mathrm{ABC}$ transporter and has been detected more frequently in E. faecalis than in E. faecium isolates. The $c f r$ gene also confers the same resistance; it encodes an rRNA methyltransferase that modifies the adenine residue at position 2503 in domain $\mathrm{V}$ of the $23 \mathrm{~S}$ rRNA. Besides resistance to oxazolidinones and phenicols, it also confers resistance to lincosamides, pleuromutilins, and streptogramin A (23). The spread of these genes could significantly limit treatment options for MDR bacteria infections (33). In our experiments, the resistance of E. faecalis and E. faecium to linezolid was also very high, reaching $100 \%$ and $83 \%$. The detection rates of optrA and $c f r$ were extreme opposites in the two enterococcal species, with detection rates of $0 \%$ and $96.3 \%$ in E. faecalis and $90.74 \%$ and $3.7 \%$ in E. faecium. The detection of these genes in E. faecalis was similar to that of Chen et al. (5) in a linezolid-resistant strain. However, in most reports, Enterococcus spp. are still susceptible to linezolid $(4,9,37)$.

Enterococci have different resistance strengths to different types of $\beta$-lactam antibiotics (16). In our study, antimicrobial susceptibility tests to penicillin and ampicillin were carried out, and demonstrated prevalence rates of E. faecalis and E. faecium resistant to ampicillin of $55.6 \%$ and $88.9 \%$, respectively and rates for the isolates resistant to penicillin of $61.1 \%$ and
90.7\%. Enterococcus faecalis isolates were more susceptible to $\beta$-lactams than E. faecium isolates, but susceptibility to aminoglycosides was higher in E. faecium isolates than E. faecalis isolates. The drug resistance rates of E. faecalis to gentamicin and streptomycin were $48.2 \%$ and $33.3 \%$ and those of E. faecium were $24.1 \%$ and $27.8 \%$.

For vancomycin resistance, we observed significant differences in the susceptibility of E. faecalis and E. faecium, with resistance rates of $55.6 \%$ and $16.6 \%$, respectively. The two genotypes vanA and vanB are the most frequent among vancomycin-resistant strains. The detection rates of E. faecalis and E. faecium with the vanA gene were $92.59 \%$ and $46.3 \%$, respectively, while isolates with $\operatorname{van} B$ were not detected, which was inconsistent with the resistance rate to vancomycins. Ribeiro et al. (29) reported that even when the vanA gene was detected, there was no resistance to vancomycin. In an investigation of oral dental diseases, oral isolates of E. faecalis were sensitive to vancomycin, which was a favourable finding (27). At the same time, we observed that the isolates were resistant to antibiotics that were no longer used; the possible explanation might be the incorporation of resistance genes into the host chromosome or the physical linkage of the antibiotic genes on the plasmid.

The presence of virulence-associated determinants and antibiotic-resistant phenotypes may enhance the pathogenesis of the Enterococcus strains due to increased adhesion, colonisation, extracellular production of enzymes, and evasion of the host immune response.

E. faecalis isolates harboured significantly more virulence-associated determinants than E. faecium isolates in previously reported data (36). In our experiment, only four virulence-associated determinants were detected; namely, the efaA, gelE, asal, and ace genes, but the detection rate for them was above $85 \%$ and higher in E. faecalis than in E. faecium. The virulence-associated determinants carried by $83.33 \%$ (90/108) of the isolates were of efaA-gelE-asal-ace type. In our study, gelE was extensively present in both E. faecalis and E. faecium isolates $(98.1 \%$ and $87.0 \%$, respectively), similarly to the results of Landete et al. (17) ( $81 \%$ and $60 \%$, respectively).

Genes for enterococcal surface protein and cell wall adhesins (espfm, espfs, efaAfm, and efaAfs) were as frequent in their corresponding species as they were found to be by Togay et al. (34). In our study, efa $A$ was found in $98.1 \%$ of E. faecalis and $85.2 \%$ of E. faecium strains, but the esp gene was not detected. This phenomenon is a contrary finding to that of Creti et al. (7) and Martin et al. (19), who both discovered a high incidence of these genes in Enterococcus spp. isolates. In this study, up to $98.1 \%$ of E. faecalis isolates were gelE-positive and $92.6 \%$ were asal-positive, which is consistent with previous studies and provides further evidence that these virulence-associated determinants are widely distributed among E. faecalis strains (24). 
Interestingly, the $h y l$ and $c y l A$ gene detection rates were $0 \%$, making results similar to those of Creti et al. (7) but consistent with other previous studies (22). An $87 \%$ proportion of E. faecalis isolates and $85.2 \%$ of E. faecium isolates were ace-positive.

In summary, our data illustrate that giant panda saliva presents a reservoir of Enterococcus spp. strains with multi-drug resistance and these isolates carry some virulence-associated determinants that may increase the risk of disease. Consequently, continued monitoring of Enterococcus spp. for antibiotic resistance and virulence-associated determinants should be performed in giant pandas' oral cavities that will help to establish strategies for prevention and surveillance of greater virulence and resistance in these bacteria as pathogens for this endangered species.

Conflict of Interests Statement: The authors declare that there is no conflict of interests regarding the publication of this article.

Financial Disclosure Statement: The current study was supported by the Chengdu Giant Panda Breeding Research Foundation (CPF2017-12) and Special Fund for Forestry Reform and Development of Wolong Special Administrative Region of Sichuan Province (510000-02-064387).

Animal Rights Statement: This study protocol was reviewed and approved by the Research Ethics Committee and the Animal Ethical Committee of Sichuan Agricultural University under permit number DYY-2018403006. Prior to the collection of saliva specimens from captive giant pandas, permission was obtained from the Chengdu Research Base of Giant Panda Breeding in the Sichuan Province, China.

\section{References}

1. Al-Ahmad A., Ameen H., Pelz K., Karygianni L., Wittmer A., Anderson A.C., Spitzmüller B., Hellwig E.: Antibiotic resistance and capacity for biofilm formation of different bacteria isolated from endodontic infections associated with root-filled teeth. J Endod 2014, 40, 223-230, doi: 10.1016/j.joen.2013.07.023.

2. Arias C.A., Murray B.E.: The rise of the Enterococcus: beyond vancomycin resistance. Nat Rev Microbiol 2012,10, 266-278, doi: 10.1038/nrmicro2761.

3. Bai B., Hu K., Li H., Yao W., Li D., Chen Z., Cheng H., Zheng J., Pan W., Deng M., Liu X., Lin Z., Deng Q., Yu Z.: Effect of tedizolid on clinical Enterococcus isolates: in vitro activity, distribution of virulence factor, resistance genes and multilocus sequence typing. FEMS Microbiol Lett 2018, 365, doi: 10.1093/femsle/fnx284.

4. Càmara J., Camoez M., Tubau F., Pujol M., Ayats J., Ardanuy C., Domínguez MÁ.: Detection of the Novel optrA Gene Among Linezolid-Resistant Enterococci in Barcelona, Spain. Microb Drug Resist 2019, 25, 87-93, doi: 10.1089/mdr.2018.0028.

5. Chen H., Wang X., Yin Y., Li S., Zhang Y., Wang Q., Wang H.: Molecular characteristics of oxazolidinone resistance in enterococci from a multicenter study in China. BMC Microbiol 2019, 19, 162, doi: 10.1186/s12866-019-1537-0.
6. Clinical and Laboratory Standards Institute: Performance Susceptibility Testing; Twenty-Fifth Informational Supplement. CLSI document M100-S25. CLSI, Wayne, 2015.

7. Creti R., Imperi M., Bertuccini L., Fabretti F., Orefici G., Di Rosa R., Baldassarri L.: Survey for virulence determinants among Enterococcus faecalis isolated from different sources. J Med Microbiol 2004, 53,13-20, doi: 10.1099/jmm.0.05353-0.

8. Falagas M.E., Koletsi P.K., Bliziotis I.A.: The diversity of definitions of multidrug-resistant (MDR) and pandrug-resistant (PDR) Acinetobacter baumannii and Pseudomonas aeruginosa. J Med Microbiol 2006, 55, 1619-1629, doi: 10.1099/ jmm.0.46747-0.

9. Flamm R.K., Farrell D.J., Mendes R.E., Ross J.E., Sader H.S., Jones R.N.: LEADER surveillance program results for 2010: an activity and spectrum analysis of linezolid using 6801 clinical isolates from the United States (61 medical centers). Diagn Microbiol Infect Dis 2012, 74, 54-61, doi: 10.1016/ j.diagmicrobio.2012.05.012.

10. Guerrero-Ramos E., Cordero J., Molina-González D., Poeta P., Igrejas G., Alonso-Calleja C., Capita R.: Antimicrobial resistance and virulence genes in enterococci from wild game meat in Spain. Food Microbiol 2016, 53, 156-164, doi: 10.1016/ j.fm.2015.09.007.

11. Jahan M., Zhanel G.G., Sparling R., Holley R.A.: Horizontal transfer of antibiotic resistance from Enterococcus faecium of fermented meat origin to clinical isolates of E. faecium and Enterococcus faecalis. Int J Food Microbiol 2015, 199, 78-85, doi: 10.1016/j.ijfoodmicro.2015.01.013

12. Kim M.C., Woo G.J.: Characterization of antimicrobial resistance and quinolone resistance factors in high-level ciprofloxacinresistant Enterococcus faecalis and Enterococcus faecium isolates obtained from fresh produce and fecal samples of patients. J Sci Food Agric 2017, 97, 2858-2864, doi: 10.1002/jsfa.8115.

13. Kim Y.B., Seo H.J., Seo K.W., Jeon H.Y., Kim D.K., Kim S.W., Lim S.K., Lee Y.J.: Characteristics of High-Level CiprofloxacinResistant Enterococcus faecalis and Enterococcus faecium from Retail Chicken Meat in Korea. J Food Prot 2018, 81,1357-1363, doi: 10.4315/0362-028X.JFP-18-046.

14. Kim Y.B., Seo K.W., Son S.H., Noh E.B., Lee Y.J.: Genetic characterization of high-level aminoglycoside-resistant Enterococcus faecalis and Enterococcus faecium isolated from retail chicken meat. Poult Sci 2019, 98, 5981-5988, doi: 10.3382/ps/pez403.

15. Kouidhi B., Zmantar T., Mahdouani K., Hentati H., Bakhrouf A..: Antibiotic resistance and adhesion properties of oral Enterococci associated to dental caries. BMC Microbiol 2011, 11, 155, doi: 10.1186/1471-2180-11-155.

16. Kristich C.J, Rice L.B., Arias C.A.: Enterococcal InfectionTreatment and Antibiotic Resistance. In: Enterococci: From Commensals to Leading Causes of Drug Resistant Infection, edited by M.S. Gilmore, D.B. Clewell, Y. Ike, N. Shankar, Massachusetts Eye and Ear Infirmary, Boston, 2014.

17. Landete J.M., Peirotén Á., Medina M., Arqués J.L., RodríguezMínguez E.: Virulence and Antibiotic Resistance of Enterococci Isolated from Healthy Breastfed Infants. Microb Drug Resist 2018, 24, 63-69, doi: 10.1089/mdr.2016.0320.

18. Linhares I., Raposo T., Rodrigues A., Almeida A.: Frequency and antimicrobial resistance patterns of bacteria implicated in community urinary tract infections: a ten-year surveillance study (2000-2009). BMC Infect Dis 2013, 13, 19, doi: 10.1186/14712334-13-19.

19. Martin B., Garriga M., Hugas M., Aymerich T.: Genetic diversity and safety aspects of enterococci from slightly fermented sausages. J Appl Microbiol 2005, 98, 1177-1190, doi: 10.1111/j.1365-2672.2005.02555.x.

20. Martín-Platero A.M., Valdivia E., Maqueda M., Martínez-Bueno M.: Characterization and safety evaluation of enterococci isolated from Spanish goats' milk cheeses. Int J Food Microbiol 2009, 132, 24-32, doi: 10.1016/j.ijfoodmicro.2009.03.010.

21. McBride S.M., Coburn P.S., Baghdayan A.S., Willems R.J., Grande M.J., Shankar N., Gilmore M.S.: Genetic variation and 
evolution of the pathogenicity island of Enterococcus faecalis. J Bacteriol 2009, 191, 3392-3402, doi: 10.1128/JB.00031-09.

22. Medeiros A.W., Pereira R.I., Oliveira D.V., Martins P.D., d'Azevedo P.A., Van der Sand S., Frazzon J., Frazzon A.P.: Molecular detection of virulence factors among food and clinical Enterococcus faecalis strains in South Brazil. Braz J Microbiol 2014, 45, 327-332, doi: 10.1590/S1517-83822014005000031.

23. Miller W.R., Munita J.M., Arias C.A.: Mechanisms of antibiotic resistance in enterococci. Expert Rev Anti Infect Ther 2014, 12, 1221-1236, doi: 10.1586/14787210.2014.956092.

24. Moraes P.M., Perin L.M., Todorov S.D., Silva A. Jr., Franco B.D., Nero L.A.: Bacteriocinogenic and virulence potential of Enterococcus isolates obtained from raw milk and cheese. J Appl Microbiol 2012, 113, 318-328, doi: 10.1111/j.13652672.2012.05341.x.

25. Okui A., Soga Y., Kokeguchi S., Nose M., Yamanaka R., Kusano N., Morita M.: Detection of Identical Isolates of Enterococcus faecalis from the Blood and Oral Mucosa in a Patient with Infective Endocarditis. Intern Med 2015, 54, 1809-1814, doi: 10.2169/ internalmedicine.54.3223.

26. Paganelli F.L., Willems R.J., Leavis H.L.: Optimizing future treatment of enterococcal infections: attacking the biofilm? Trends Microbiol 2012, 20, 40-49, doi: 10.1016/ j.tim.2011.11.001.

27. Pinheiro E.T., Gomes B.P., Drucker D.B., Zaia A.A., Ferraz C.C., Souza-Filho FJ. Antimicrobial susceptibility of Enterococcus faecalis isolated from canals of root filled teeth with periapical lesions. Int Endod J 2004, 37, 756-763, doi: 10.1111/j.13652591.2004.00865.x.

28. Ran S., Wang J., Jiang W., Zhu C., Liang J.: Assessment of dentinal tubule invasion capacity of Enterococcus faecalis under stress conditions ex vivo. Int Endod J 2015, 48, 362-372, doi: 10.1111/iej.12322.

29. Ribeiro T., Abrantes M., Lopes Mde F., Crespo M.T.: Vancomycin-susceptible dairy and clinical enterococcal isolates carry vanA and vanB genes. Int J Food Microbiol 2007, 113, 289-295, doi: 10.1016/j.ijfoodmicro.2006.08.010.

30. Sattari-Maraji A., Jabalameli F., Node Farahani N., Beigverdi R., Emaneini M.: Antimicrobial resistance pattern, virulence determinants and molecular analysis of Enterococcus faecium isolated from children infections in Iran. BMC Microbiol 2019, 19, 156, doi: 10.1186/s12866-019-1539-y.

31. Singhal A., Sharma R., Jain M., Vyas L.: Hospital and Community Isolates of Uropathogens and their Antibiotic Sensitivity Pattern from a Tertiary Care Hospital in North West India. Ann Med Health Sci Res 2014, 4, 51-56, doi: 10.4103/2141-9248.126611.

32. Tamang M.D., Moon D.C., Kim S.R., Kang H.Y., Lee K., Nam H.M., Jang G.C., Lee H.S., Jung S.C., Lim S.K.: Detection of novel oxazolidinone and phenicol resistance gene optrA in enterococcal isolates from food animals and animal carcasses. Vet Microbiol 2017, 201, 252-256, doi: 10.1016/j.vetmic. 2017.01.035

33. Tian Y., Yu H., Wang Z.: Distribution of acquired antibiotic resistance genes among Enterococcus spp. isolated from a hospital in Baotou, China. BMC Res Notes 2019, 12, 27, doi: 10.1186/s13104-019-4064-z.

34. Toğay S.O., Keskin A.C., Açik L., Temiz A.: Virulence genes, antibiotic resistance and plasmid profiles of Enterococcus faecalis and Enterococcus faecium from naturally fermented Turkish foods. J Appl Microbiol 2010, 109, 1084-1092, doi: 10.1111/j.1365-2672.2010.04763.x.

35. Vankerckhoven V., Van Autgaerden T., Vael C., Lammens C., Chapelle S., Rossi R., Jabes D., Goossens H.: Development of a multiplex PCR for the detection of asa1, gelE, cylA, esp, and hyl genes in enterococci and survey for virulence determinants among European hospital isolates of Enterococcus faecium. J Clin Microbiol 2004, 42, 4473-4479, doi: 10.1128/JCM.42.10.44734479.2004

36. Wioleta C.W., Anna Z., Łucja L.T.: Virulence factors of Enterococcus spp. presented in food. LWT 2017, 75, doi: 10.1016/j.lwt.2016.10.026.

37. Zhou W., Gao S., Xu H., Zhang Z., Chen F., Shen H., Zhang C.: Distribution of the optrA gene in Enterococcus isolates at a tertiary care hospital in China. J Glob Antimicrob Resist 2019, 17, 180-186, doi: 10.1016/j.jgar.2019.01.001.

38. Zhu X., Wang Q., Zhang C., Cheung G.S., Shen Y.: Prevalence, phenotype, and genotype of Enterococcus faecalis isolated from saliva and root canals in patients with persistent apical periodontitis. J Endod 2010, 36, 1950-1955, doi: 10.1016/j.joen.2010.08.053. 